\title{
Results of laboratory tests not accessed in Brazilian private laboratories
}

\author{
Resultados de exames laboratoriais não acessados em laboratórios privados brasileiros
}

Wilson Shcolnik ${ }^{1,2}$; Alex Galoro ${ }^{1,3}$; Marcelo Lorencin'; Rodolpho N. Donini'; Diogo Jeronimo5

1. Sociedade Brasileira de Patologia Clínica/Medicina Laboratorial (SBPC/ML), Rio de Janeiro, Rio de Janeiro, Brazil. 2. Grupo Fleury, São Paulo, São Paulo, Brazil. 3. Grupo Sabin, Brasília, Distrito Federal, Brazil. 4. SHIFT Consultoria e Sistemas, São José do Rio Preto, São Paulo, Brazil. 5. Controllab, Rio de Janeiro, Rio de Janeiro, Brazil.

\begin{abstract}
Background: Laboratory medicine is an important part of the health care system and directly contributes to preventive actions, diagnostics, treatment, and management of diseases. The level and quality of laboratory resources utilization have been frequently questioned. A dissemination of conflicting data regarding the amount of laboratory tests not accessed by the requesting doctors or by the patients themselves is observed, although very often the sources and methodologies used to access these numbers are not properly clarified. Objective: The objective of this study was to obtain data on access to tests results performed in Brazilian private clinical analysis laboratories using the laboratory information system developed by SHIFT Consultoria e Sistemas (Consulting and Systems). Methods: The information was extracted from 81 laboratories, responsible for the performance of 93,240,651 tests, collected from 7,067,087 patients. Results: The total number of tests not accessed, considering all the regions, was 5,071,454, corresponding to a proportion of $5.4 \%$. Due to the potential risks of adverse events or impacts on diagnostic and treatment management, including the economic impacts due to prolonged hospitalization time, the $17.9 \%$ proportion which was found to correspond to "not accessed" tests showing "abnormal" results. It is of particular concern, mainly if we observe that from these, $2.5 \%$ were related to "abnormal" test results processed by laboratories working in hospital units. Conclusion: Due to the relevance of the theme, Sociedade Brasileira de Patologia Clínica/Medicina Laboratorial (SBPC/ML), will keep encouraging the monitoring and utilization of adequate laboratory resources, in order to enable sustainable health care systems.
\end{abstract}

Key words: hospital laboratory; clinical laboratory services; patient safety; diagnostic error; laboratory information systems.

\section{RESUMO}

Introdução: A medicina laboratorial é uma parte importante do sistema de saúde e contribui diretamente para ações preventivas e de diagnósticos, tratamento e monitoramento de doenças. O nivel e a qualidade da utilização de recursos laboratoriais são frequentemente questionados. Observa-se uma disseminação de dados conflitantes em relação à quantidade de resultados de exames laboratoriais não acessados pelos médicos solicitantes ou pelos próprios pacientes, embora muitas vezes as fontes e as metodologias utilizadas para acessar esses números não sejam devidamente esclarecidas. Objetivo: O objetivo deste estudo foi obter dados sobre o acesso aos resultados de testes realizados em laboratórios de análises clinicas privados brasileiros que utilizam o sistema de informações laboratoriais desenvolvido pela SHIFT Consultoria e Sistemas. Métodos: As informações foram extraídas de 81 laboratórios, responsáveis pelo desempenho de 93.240.651 testes, coletados de 7.067.087 pacientes. Resultados: 0 total de resultados de exames não acessados, considerando todas as regiões, foi de 5.071.454, correspondendo a uma proporção de 5,4\%. Diante dos riscos potenciais de eventos adversos ou de impactos na gestão de diagnósticos e tratamentos, inchindo os impactos econômicos decorrentes do tempo prolongado de internação, a proporção de 17,9\% encontrada correspondente a testes não acessados com resultados "anormais" épreocupante, principalmente se observarmos que 2,5\% foram relacionados com resultados

First submission on $08 / 20 / 19$; last submission on $08 / 27 / 19$; accepted for publication on 10/15/19; published on 12/20/19 
de testes "anormais" processados por laboratórios que trabalham em unidades hospitalares. Conclusão: A Sociedade Brasileira de Patologia Clinica/Medicina Laboratorial (SBPC/ML), diante da relevância do tema, continuará estimulando o monitoramento e a utilização de recursos laboratoriais adequados, a fim de permitir sistemas de saúde sustentáveis.

Unitermos: laboratório hospitalar; serviços de laboratório clínico; segurança do paciente; erro diagnóstico; sistemas de informação em laboratório.

\section{RESUMEN}

Introducción: La medicina de laboratorio es una parte importante del sistema de salud y contribuye directamente a las acciones preventivas, diagnósticos, tratamiento y manejo de enfermedades. El nivel y la calidad de la utilización de los recursos de laboratorio se ban cuestionado con frecuencia. Se observa una diseminación de datos contradictorios sobre la cantidad de pruebas de laboratorio a las que no ban accedido los médicos solicitantes o los propios pacientes, aunque muy a menudo las fuentes y metodologías utilizadas para obtener esas cifras no se aclaran adecuadamente. Objetivo: El objetivo de este estudio fue obtener datos sobre el acceso a los resultados de las pruebas realizadas en los laboratorios de análisis clínicos privados de Brasil que utilizan el sistema de información de laboratorio desarrollado por SHIFT Consultoria e Sistemas. Métodos: La información se extrajo de 81 laboratorios, que fueron responsables del rendimiento de 93,240,651 pruebas, recolectadas de 7,067,087 pacientes. Resultados: El número total de pruebas a las que no se accedió, considerando todas las regiones, fue de 5,071,454, lo que corresponde a una proporción del 5,4\%. Ante los riesgos potenciales de eventos adversos o impactos en el manejo de diagnósticos y tratamientos, inchidos los impactos económicos debido al tiempo prolongado de hospitalización, la proporción del 17,9\% que se encontró correspondiente a las pruebas "no accedidas" muestra resultados "anormales" es preocupante, principalmente si observamos que de ellos, el 2,5\% se relacionó con resultados de pruebas "anormales" procesados por laboratorios que trabajan en la atención hospitalaria. Conclusión: Sociedade Brasileira de Patologia Clínica/Medicina Laboratorial (SBPC/ML), ante la relevancia del tema, continuará estimulando el monitoreo y la utilización de recursos de laboratorio adecuados para permitir sistemas de salud sostenibles.

Palabras clave: laboratorio de hospital; servicios de laboratorio clínico; seguridad del paciente; error diagnóstico; sistemas de información en laboratorio.

\section{INTRODUCTION}

Laboratory medicine is an important part of the health care system and directly contributes to disease preventive action, diagnosis, treatment and management ${ }^{(1)}$. Although, over the last decades, the advances in knowledge and accuracy of the equipment used in diagnostic tests have been surprising, the level and quality of using these resources have often been questioned. Obtaining a diagnosis is based on patient-related history, physical examination, and clinical observations by physicians. In addition, physicians may use laboratory tests for more information through services provided by clinical pathologists, anatomopathologists, geneticists, radiologists, and other specialists. Complementary examinations also are useful to guide decisions on the next steps in care, ruling out inappropriate interventions, providing information for effective patient care, and ensuring the value involved in the use of these resources ${ }^{(2)}$.
The Brazilian laboratory medicine sector has been repeatedly questioned - by authorities, opinion makers and health care professionals - regarding the level of access to test results. Conflicting data on the number of laboratory tests not accessed by the requesting physicians or by the patients themselves are observed, although the sources and methodologies used to survey these numbers are often unclear. Such occurrence is used, among others, to justify the increasing costs in the health care area and the waste in this sector.

In Brazil, as in other countries, outpatient laboratory and radiological examinations have historically been provided directly to patients and, in some cases, to the requesting physicians. Some clinical laboratories practice communicating with physicians for discussion of test results, which are considered good practice, but there are no standards or guarantees that this should be performed on a regular basis. Similarly, once test results are delivered to patients, there is no guarantee that the results will be evaluated by the requesting physician. 
According to Graber (2005), without knowing exactly the dimension of the lack of test results follow-up, many doctors may underestimate their extent and, therefore, not initiate actions to improve this process ${ }^{(3)}$.

\section{OBJECTIVE}

The objective of the present study was to obtain data on the access to test results performed in Brazilian private clinical analysis laboratories using the laboratory information system developed by SHIFT Consultoria e Sistemas.

\section{METHODS}

This research was carried out from a partnership of the Brazilian Society of Clinical Pathology/Laboratory Medicine [Sociedade Brasileira de Patologia Clínica/Medicina Laboratorial (SBPC/ML)] together with SHIFT Consultoria e Sistemas (Consulting and Systems).

$\mathrm{SBPC} / \mathrm{ML}$ is a Brazilian National Medical Specialty Society, founded in 1944, which operates in the field of clinical laboratories. Headquartered in the city of Rio de Janeiro, Brazil, its purpose is to bring physicians who hold the title of specialist in Clinical Pathology/Laboratory Medicine together with professionals from other specialties working in clinical laboratories, such as pharmaceutical-biochemical, biomedical, biologists, as well as companies in the sector. SBPC/ML organizes professional habilitation and qualification projects, and achieves them through activities aimed at teaching, research and scientific dissemination in Laboratory Medicine, with the main goal of preserving the health of the population.

SHIFT is a laboratory information system (LIS) Development Company, founded 25 years ago and, currently, has 134 user laboratories located throughout Brazil. These laboratories annually attend about 35 million patients in their collection units and perform 200 million tests (2015 data), representing approximately $16 \%$ of the Brazilian laboratory test processing market, estimated at 1.25 billion tests per year.

In the period preceding the research, letters were sent to technical directors of the laboratories using the LIS developed by SHIFT, containing information on the research to be carried out, their respective objectives, aiming at the compliance of the laboratories through authorization, assuring the confidentiality of individual laboratory information of each laboratory.
From May 1, 2016 to May 1, 2017, data regarding the production of tests performed in the last 365 days by each laboratory that formally agreed participating in the research were evaluated separately, and through the execution of the computational algorithm developed by the SHIFT technical team.

Thus, access to data from the last year of operation of each participating clinical laboratory, was planned. The final date that made up the research period corresponded to the previous 60 days from the date of execution of the computational algorithm. Such definition was due to the possibility of including examinations whose performance requires longer period, and whose results were available within 60 days after their completion. Among the data obtained are included:

- geographic region of clinical laboratories, with the North and Northeast regions being determined together, as they have a smaller number of laboratories;

- type of insertion in Brazilian health care systems (public and supplementary);

- type of environment in which patients whose tests were collected (outpatient and inpatient) were located;

- cyto and anatomopathological examinations supply;

- total number of patients attended and number of tests performed during the survey period;

- total number of test results not accessed;

- number of test results not accessed in outpatient and inpatient settings, by geographic region studied;

- number of "abnormal" test results among the not accessed results;

- total number of "abnormal" test results among the not accessed results in outpatient and inpatient settings, by geographic region studied.

The following were considered as "accessed test results": i) results that were printed, whether or not recorded in the information system - a current practice in laboratories is printing as it demand; and ii) results that were consulted by the patient or the requesting physician by electronic means.

The printed test results, but lacking the respective delivery record in the system, although considered as accessed, were also registered separately.

The electronic means of access to the result considered were: i) the Internet (laboratory site); ii) mobile devices and mobile applications, and iii) emailing from the LIS. 
The following were considered as "not accessed test results": i) the results of tests that were processed and released with no delivery record in the SHIFT information system, or were not printed; ii) results with no evidence of consultations by the electronic means mentioned above; iii) the results of tests of hospitalized patients with no registration of delivery by the SHIFT LIS, or that were not printed - there was no distinction between hospital laboratories that were integrated or not with hospitals information systems by LIS.

All tests performed were computed individually, as each patient may have performed more than one test and the results of only some of these tests may not have been accessed.

The following were not considered in the research: i) the test results that, on the date of algorithm execution, were not available to the patient. That is, the cases of results that had not yet been released were excluded from the totals (since they were processing, including the cases of replicate analysis to confirm results); ii) tests whose materials had not yet been delivered to the laboratory, regardless of the reason; iii) results of tests delivered by laboratories directly to other institutions with whom they have a contract (clinics, hospitals, etc.), since the control of delivery to the final patient is not managed or controlled by the laboratory, which prevents registration by SHIFT LIS; iv) results of tests performed for patients who were attended by the Public Health System [Sistema Único de Saúde (SUS) ], due to the way the results are delivered and distributed to patients of this system (most of the time distribution to patients is performed by the Basic Health Units and/or hospitals, manually, which prevents the control by SHIFT LIS).

Those test results that were outside the limits set as "reference intervals" by each participating laboratory were considered "abnormal" test results.

For tests consisting of multiple parameters/analytes (such as routine urine test, lipid profile, etc.), those who had at least one of their parameters outside the specified "reference range" were classified as results outside the limits of the "reference ranges".

Those that could not be compared with the limits of "reference ranges", due to the lack of parameterization in the laboratory information system or formatting these intervals in tables, where there are no individual fields predetermined for inclusion of values of each analyte, which prevented the comparison through the computational algorithm developed, were considered as "not classified" test results.

In data analysis, the different sizes of the participating laboratories were not considered.

Graphical and statistical analyzes were performed using Excel for Windows and R 3.3.3 software( ${ }^{(4)}$.
The statistical approach employed nonparametric tests and computational methods, applied to the rates of "not accessed" test results compared to the total of tests performed, to the rates of abnormal test results, to the health care environments and the respective geographic regions. Such rates were analyzed using the bootstrap method ${ }^{(5)}$. We also analyzed the rates of abnormal test results, among those not accessed, according to the type of patient care (outpatient or inpatient). In this case, two distinct analyzes were applied: the first investigated the association between the type of health care and the geographic region, to identify trends of increase or decrease in rates; the second investigated possible differences between the percentages obtained the by type of health care. To investigate the association between the geographic region and the type of health care, and thus to investigate trends between these rates, the Chi-Square test for Independence was performed. To test the difference between rates according to the type of health care, the Mann-Whitney $U$ test was performed. The significance level associated with this study was $p<0.05$ and $95 \%$ confidence interval.

\section{RESULTS}

Information was extracted from 81 laboratories, representing $69 \%$ of customers using the LIS by SHIFT and who agreed to participate in this survey.

The participating laboratories were responsible for the performance of 93,240,651 tests, collected from 7,067,087 patients. The average number of tests performed per patient was 13.1. From the total tests, 43,185,695 (46.3\%) were performed by laboratories located in the Southeast region; 33,895,565 (36.3\%) in the Midwest region; 11,793,635 (12.7\%) in the North and Northeast region, and 4,365,756 (4.7\%) in the South region, as shown in Figure.

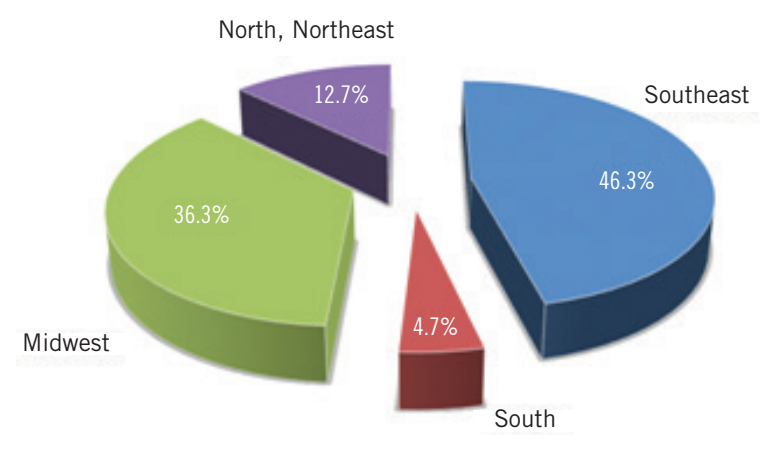

FIGURE - Distribution of tests performed by geographic region 
From the total participating laboratories, $49(60 \%)$ assisted the beneficiary customer exclusively from the private supplementary health care system, while $32(40 \%)$ laboratories assisted the beneficiary customer from both the public health care system and the private supplementary health care system.

From the 81 laboratories that agreed to participate in the research, 64 (79\%) underwent cytopathological and pathological examinations, or outsourced such procedures to other laboratories.

Most tests performed by the participating laboratories were performed for outpatients $[87,695,489$ (94.1\%)], and the remaining tests were performed for inpatients [5,545,162 (5.9\%)].

Table 1 presents absolute numbers and respective rates of tests performed by laboratories that agreed to participate in the study, by type of environment and by geographic region.

The total number of test results not accessed, considering all the selected regions, was 5,071,454, corresponding to a rate of 5.4\%. The highest rate of test results not accessed was found in the North and Northeast, followed by the South, Southeast and Midwest, as shown in Table 2.

From the total number of not accessed test results $(5,071,454)$, the rate of "abnormal" results, considering all the regions verified, it was $17.9 \%$ corresponding to 911,641 tests. The number of laboratory tests with "abnormal" not accessed results, by Brazilian geographic region, according to the criteria already described, and their respective rate are presented in Table 3.

TABLE 1 - Absolute numbers and their rates of tests performed by 81 laboratories from 1 May, 2016 to 1 May, 2017, by type of environment and by geographical region

\begin{tabular}{ccccc}
\hline Region & Outpatient & $\%$ & Inpatient & $\%$ \\
\hline Southeast & $39,860,672$ & 92.3 & $3,325,023$ & 7.7 \\
South & $4,254,670$ & 97.5 & 111,086 & 2.5 \\
Midwest & $32,993,291$ & 97.3 & 902,274 & 2.7 \\
North, Northeast & $10,586,856$ & 89.8 & $1,206,779$ & 10.2 \\
All regions & $87,695,489$ & 94.1 & $5,545,162$ & 5.9 \\
\hline
\end{tabular}

TABLE 2 - Absolute numbers and respective rates of "not accessed" laboratory test results performed by 81 laboratories from May 1, 2016 to May 1, 2017, by Brazilian geographic region

\begin{tabular}{ccccc}
\hline Region & Total tests performed & $\%$ & Total not accessed test results & $\%$ \\
\hline Southeast & $43,185,695$ & 46.3 & $2,607,502$ & 6 \\
South & $4,365,756$ & 4.7 & 266,752 & 6.1 \\
Midwest & $33,895,565$ & 36.3 & $1,137,697$ & 3.4 \\
North, Northeast & $11,793,635$ & 12.7 & $1,059,503$ & 9 \\
All regions & $93,240,651$ & 100 & $5,071,454$ & 5.4 \\
\hline Bootstrap range 4.08\%; 8.25\%, considering & $\mathrm{p}<0.05$. & &
\end{tabular}

TABLE 3 - Absolute number of not accessed test results, performed by 81 laboratories in the period between May 1, 2016 and May 1, 2017, which presented "abnormal" values and their respective rates, by Brazilian geographic region

\begin{tabular}{cccc}
\hline Region & $\begin{array}{c}\text { Number of not accessed } \\
\text { test results }\end{array}$ & $\begin{array}{c}\text { Number of "abnormal" not } \\
\text { accessed test results }\end{array}$ & $\%$ \\
\hline Southeast & $2,607,502$ & 418,627 & 16 \\
South & 266,752 & 44,364 & 16.6 \\
Midwest & $1,137,697$ & 233,999 & 20 \\
North, Northeast & $1,059,503$ & 214,655 & 20.2 \\
All regions & $5,071,454$ & 911,641 & 17.9 \\
\hline
\end{tabular}

Bootstrap range $16.3 \%$ to $20.1 \%$, considering $\mathrm{p}<0.05$.

Confidence intervals obtained for the rates of interest (not accessed test results compared to the total, and "abnormal" test results among those results not accessed) indicated peaks in certain regions. Such rates, however, revealed no association between the type of care (outpatient or inpatient) and the geographic region of the laboratory.

Not accessed results considered "not classified", according to criteria already described, corresponded to 2,184,604 (43.1\%).

As observed in Table 4, the total rate of not accessed test results with "abnormal" results found in an outpatient setting, considering all the verified regions, was $0.9 \%$, and the regional rates found in this setting ranged from $0.6 \%$ to $1.6 \%$. The total rate of not accessed test results with "abnormal" results verified in the hospital environment, considering all the verified regions, was $2.5 \%$, and the regional rate

TABLE 4 - Absolute numbers of not accessed test results performed by 81 laboratories in the period between May 1, 2016 and May 1, 2017, which presented "abnormal" values, and their respective rates, by type of environment and Brazilian geographic region

\begin{tabular}{|c|c|c|c|c|c|c|c|}
\hline Region & Total tests performed & $\begin{array}{l}\text { Total of tests performed, } \\
\text { outpatient clinic }\end{array}$ & $\begin{array}{l}\text { Total of not accessed } \\
\text { "abnormal" results, } \\
\text { outpatient clinic }\end{array}$ & $\%$ & $\begin{array}{c}\text { Total of tests performed, } \\
\text { inpatient }\end{array}$ & $\begin{array}{c}\text { Total not accessed results, } \\
\text { inpatient }\end{array}$ & $\%$ \\
\hline Southeast & $43,185,695$ & $39,860,672$ & 345,152 & 0.9 & $3,325,023$ & 73,563 & 2.2 \\
\hline South & $4,365,756$ & $4,254,670$ & 43,897 & 1 & 111,086 & 467 & 0.4 \\
\hline Midwest & $33,895,565$ & $32,993,291$ & 214,168 & 0.6 & 902,274 & 19,827 & 2.1 \\
\hline North, Northeast & $11,793,635$ & $10,586,856$ & 167,051 & 1.6 & $1,206,779$ & 47,604 & 3.9 \\
\hline All regions & $93,240,651$ & $87,695,489$ & 770,268 & 0.9 & $5,545,162$ & 141,461 & 2.5 \\
\hline
\end{tabular}

Bootstrap range $0.85 \% ; 3.45 \%$, considering $\mathrm{p}<0.05$. 
ranged from 0.4 to $3.9 \%$. The highest rate of not accessed test results with "abnormal" results in the hospital setting was found in the North and Northeast regions (3.9\%).

According to the results of the statistical tests, the rates of not accessed test results did not reveal an association between the environment in which the laboratory assistance was performed and the geographic region of the laboratory. Likewise, the rates of test results not accessed with "abnormal" results also revealed no association between the environment in which laboratory assistance was performed and the geographic region of the laboratory.

The number of tests whose results were only "printed", with no the corresponding registration in the laboratory computer system was $9,960,531(10.7 \%)$.

\section{DISCUSSION}

Health care spending is one of the main economic drivers in most countries. Recent studies show that actual spending on laboratory tests represents $1.4 \%, 1.6 \%$ and $2.3 \%$ of total health spending in Germany, Italy, and the United States, respectively. On the other hand, spending observed in the United States of America and European Union countries has not produced the expected health care benefits. Thus, future interventions in the laboratory sector are expected to be directed to the level of resource utilization, the search for efficiency and the elimination of waste ${ }^{(6-8)}$.

The World Alliance for Patient Safety has identified failures in tracking test results as one of the key processes contributing to unsafe patient care ${ }^{(9)}$.

According to Rodrigues-Borja et al. (2014) ${ }^{(10)}$, the delay in consulting the results of tests by doctors influences the quality of health care.

There is already consistent evidence to show that the tests management process represents a significant source of error and harm to patients ${ }^{(11-13)}$.

According to Poon et al. (2004) ${ }^{(14)}$, delays in consulting test results are frequently observed, and approximately $20 \%$ of these failures result in harm to the patient.

Sung et al. (2006) $)^{(15)}$, reported that 1 to $10 \%$ of abnormal test results not accessed by requesters, represented potential adverse health consequences for patients.

In Australia, 2011, the consequences of delayed or lack of follow-up of test results were described in a report by the Clinical
Excellence Commission in New South Wales, Australia, which reported $11 \%$ of incidents progressing to deaths and $32 \%$ of incidents with important consequences for patients, including loss of body function ${ }^{(16)}$.

Data generated by the SBPC/ML and Controllab Laboratory Indicators Program to monitor laboratory quality indicators, among others, revealed that in the first half of 2017 were generated by 22 participating laboratories located in different Brazilian regions, 8,838,590 reports containing a variable number of test results, of which 602,187 (6.8\%) were considered "not accessed". Printed reports, as well as communications by telephone, SMS and WhatsApp message, consulted by smartphone applications and the Internet portals, were considered as accessed. The median of "not accessed" reports by participants, however, was only $1.7 \%$.

The present work evaluated a sample of tests performed by 81 Brazilian clinical laboratories, of varying sizes, that use the LIS developed by SHIFT Consultoria e Sistemas. Considering that the total number of laboratory tests performed in Brazil is around 1.25 billion/year, the sample represented here was satisfactory, representing approximately $7.8 \%$ of this total. Not participating in this survey the laboratories that assist the SUS only.

The rate of not accessed laboratory test results (5.4\%) found in the present study was lower than the citations reported by the Brazilian media, although in these citations the number of reports that were considered, actually contain a variable number of examinations. This rate is also lower than the error variation range in monitoring of laboratory tests described in the systematic review carried out by Callen et al. (2012) ${ }^{(17)}$. These authors considered the absence of recorded actions related to the visualization of results in manual and electronic medical records as failures, and found, in retrospective studies, $6.8 \%$ to $62 \%$ of not accessed test results performed in an outpatient setting.

Due to the potential risks of adverse events or impacts on the management of diagnoses and treatments, including economic impacts due to prolonged hospitalizations, the $17.9 \%$ rate found corresponding to "not accessed" test results that presented "abnormal" results is worrying, especially if when observing that, from these, $2.5 \%$ referred to "abnormal" tests results performed by laboratories that work in hospital care. Callen et al. (2011) ${ }^{(18)}$ reported a rate of $20.04 \%$ to $61.9 \%$ of not accessed test results performed for hospitalized patients.

The usual way of delivery and the impossibility of controlling access to test results for patients in the public health system, did not allow comparisons of data from test results performed in this system with data from patients using the private supplementary system. 
Considering that some clinical laboratories that agreed to participate in this study are integrated with hospital information systems, it is possible that part of the test results considered as "not accessed", due to the lack of access registration in the SHIFT information system, was actually accessed in the hospital information system. In this situation, the rate of not accessed test results performed by hospital patients may be lower than that found.

As a high rate of not accessed test results [2,184,604 (43.1\%)] could not be classified in relation to the reference ranges because it is impossible to capture this information, or due to the indetermination of these values in their information systems, it is possible that the number of not accessed test results with "abnormal" results may be even higher than the percentage found.

Asignificant number of laboratories [64from 81 (79\%)] reported performing cytopathological and pathological examinations, or outsourcing such examinations to other laboratories. However, this research did not determine the specific rate of these tests, among the not accessed test results. Due to the nature of these tests, when there are positive reports, there is a potential occurrence of diagnostic delays with potential impacts on patients.

Data obtained in Brazil in 2016, by the Regional Center for Studies on the Development of the Information Society [Centro Regional de Estudos para o Desenvolvimento da Sociedade da Informação (Cetic.br)] through "ICT Health research" on infrastructure, availability of information and communication technologies, and applications, based on them, in health facilities has revealed, among others, the rates of the Internet use and the availability of laboratory test results in the last 12 months. These rates and the comparison with the rates of not accessed test results obtained in the present study are presented in Table $\mathbf{5}^{(19)}$.

Although the availability of test results over the Internet cannot be ignored as an important factor that facilitates access to results, we did not observe a direct relationship between these data and those obtained in this study.

TABLE 5 - Rates of not accessed test results by Brazilian geographic region and health facilities that used the Internet in the last 12 months, providing laboratory test results

\begin{tabular}{ccc}
\hline $\begin{array}{c}\text { Geographic } \\
\text { region }\end{array}$ & $\begin{array}{c}\text { \% of not accessed } \\
\text { test results }\end{array}$ & $\begin{array}{c}\text { \% availability of tests } \\
\text { results - Cetic data }\end{array}$ \\
\hline North, Northeast & 9 & - \\
South & 6.1 & 58 \\
Southeast & 6 & 43 \\
Midwest & 3.4 & 43 \\
North & - & 35 \\
Northeast & - & 37 \\
\hline
\end{tabular}

Cetic: Centro Regional de Estudos para o Desenvolvimento da Sociedade da Informação.
In health systems in many countries, such as the United States and the United Kingdom, it is common for test results to be returned directly to requesting physicians, although there are reports on initiatives to make results available directly to patients if physicians cannot access them ${ }^{(20)}$.

In Brazil, for more than a decade, it has been a common practice to make test results available directly to patients, either by printing the results in laboratory care units, or direct access of doctors and patients to clinical laboratory sites via the Internet. Some clinical laboratories make available to both referring physicians and patients the test results via e-mail or SMS messages on Smartphone. In the latter situation, there is no guarantee on the time period that the results will be evaluated by the requesting physician.

According to Callen et al. (2012) ${ }^{(17)}$, the loss or lack of access to test results at outpatient setting can be attributed to several factors, including: the lack of governance principles related to managing test results; the lack of integrated information systems; the multidisciplinary nature of examinations; management processes and the need to consider the role played by patients in monitoring their own test results.

According to Ferraro et al. $(2016)^{(21)}$, laboratory professionals' initiatives are necessary to enable physicians to access and know laboratory information and its interpretation, ensuring the quality and safety of the extra-analytical phase of the laboratory process.

However, according to Singh and colleagues, tracking and reporting test results, including critical results, is not as high as $100 \%$, even in organizations with sophisticated and mature electronic record systems ${ }^{(22)}$.

The possible contributions of information technology to troubleshooting access to laboratory test results include alerts on pending test results and released results, as well as decisiontracking systems and clinical actions taken based on test results received $^{(12,16)}$.

Although the data obtained in the present study were obtained by a methodology different from that conducted in other studies, the results reaffirm the need for awareness of these potential risks, for the medical class and the patients themselves, warning of possible adverse events and the costs that these represent for health care systems.

These data also reveal the existence of opportunities for clinical labs to contribute to the development of solutions for monitoring test results, thus contributing to the reduction of incidents and the achievement of better health care outcomes. 
Other studies involving laboratories using other laboratory computer systems and assessing the impact of "not accessed" laboratory test results on different health care systems are needed in order to serve as input for managers and health policy makers, besides clarifying the Brazilian society about the efficiency in using the laboratory services.

\section{RESEARCH LIMITATIONS}

Among the "abnormal, not accessed" test results, the rate corresponding to "critical values" was not determined, since these values are defined by each laboratory and may vary.

The rates of results of anatomopathological and cytological "not accessed" tests results were also not determined, nor the influence of results of "not accessed" tests in the outcomes of health care.

\section{REFERENCES}

1. Ferraro S, Braga F, Panteghini M. Laboratory medicine in the new healthcare environment. Clin Chem Lab Med. 2016; 54(4): 523-33. PubMed PMID: 26466169.

2. The NHS Atlas of Variation in Diagnostic Services. Available at: https:// ukgtn.nhs.uk/fileadmin/uploads/ukgtn/Documents/Resources/ Library/Reports_Guidelines/Right_Care_Diagnostics_Atlas_2013.pdf.

3. Graber M. Diagnostic errors in medicine: a case of neglect. Jt Comm J Qual Patient Saf. 2005; 31(2): 106-13.

4. R CORE TEAM (2017). A language and environment for statistical computing. R Foundation for Statistical Computing, Vienna, Austria. Available at: https://www.R-project.org. [accessed on: 2018, Jan 11].

5. Efron B, Tibshirani R. An introduction to the bootstrap. Chapman and Hall; 1993.

6. Lippi G, Plebani M. Laboratory economics. Risk or opportunity? Clin Chem Lab Med. 2016; 54(11): 1701-3.

7. Rohr UP, Binder C, Dieterle T, et al. The value of in vitro diagnostic testing in medical practice: a status report. PLoS One. 2016; 11(3): e0149856. doi:10.1371/journal.pone.0149856.

8. Lippi G, Mattiuzzi C. Testing volume is not synonymous of cost, value and efficacy in laboratory diagnostics. Clin Chem Lab Med. 2013; 51(2): 243-5.

9. World Alliance for Patient Safety. Summary of the evidence on patient safety: implications for research. Geneve. ISBN 9789241596541.2008.

10. Rodríguez-Borja E, Villalba-Martínez C, Carratalá-Calvo A. Enquiry time as part of turnaround time: when do our clinicians really consult our results? J Clin Pathol. 2014; 67: 642-4.

11. Improving Your Laboratory Testing Process. Content last reviewed January 2018. Agency for Healthcare Research and Quality, Rockville, MD.

\section{CONCLUSION}

The rate of laboratory test results not accessed in a data collection obtained from 81 laboratories located in different Brazilian regions was $5.4 \%$, in contrast to data released by the Brazilian media and government agencies.

Due to the importance of this theme, SBPC/ML will maintain incentives for monitoring and appropriate use of laboratory resources in order to maintain sustainable health care systems.

\section{CONFLICT OF INTERESTS}

The authors declare no conflict of interest.

Available at: http://www.ahrq.gov/professionals/quality-patient-safety/ hais/tools/ambulatory-care/labtesting-toolkit.html. [accessed on: 2018, Jan 26].

12. Dalal AK, Pesterev BM, Eibensteiner K, Newmark LP, Samal L, Rothschild JM. Linking acknowledgement to action: closing the loop on non-urgent, clinically significant test results in the electronic health record. J Am Med Inform Assoc. 2015; 22(4): 905-8. doi: 10.1093/jamia/ ocv007.

13. Hickner J, Graham DG, Elder NC, et al. Testing process errors and their harms and consequences reported from family medicine practices: a study of the American Academy of Family Physicians National Research Network. Qual Saf Health Care. 2008; 17: 194-200.

14. Poon EG, Gandhi TK, Sequist TD, et al. "I wish I had seen this test result earlier!": dissatisfaction with test result management systems in primary care. Arch Intern Med. 2004; 164: 2223-8.

15. Sung S, Forman-Hoffman V, Wilson MC, Cram P. Direct reporting of laboratory test results to patients by mail to enhance patient safety. J Gen Intern Med. 2006; 21: 1075-8.

16. Georgiou A, Lymer S, Forster M, et al. Lessons learned from the introduction of an electronic safety net to enhance test result management in an Australian mothers' hospital. J Am Med Inform Assoc. 2014; 21 : 1104-8. doi:10.1136.

17. Callen JL, Westbrook JI, Georgiou A, Li J. Failure to follow-up test results for ambulatory patients: a systematic review. J Gen Intern Med. 2012; 27(10): 1334-48. Epub 2011 Dec 20.

18. Callen JL, Georgiou A, Li J, Westbrook JL. The safety implications of missed test results for hospitalized patients: a systematic review. BMJ Qual Saf. 2011; 20: 194-9. PubMed PMID: 21300992.

19. CGI.br/NIC.br. Centro Regional de Estudos para Desenvolvimento da Sociedade da Informação (Cetic.br). Pesquisa sobre o uso das tecnologias 
de informação e comunicação nos estabelecimentos de saúde brasileiros - TIC Saúde 2016. Available at: http://cetic.br/pesquisa/saude/. [accessed on: 2017, Dec 27].

20. Kwan JL, Cram P. Do not assume that no news is good news: test result management and communication in primary care. BMJ Qual Saf. 2015; 24: $664-6$
21. Ferraro S, Braga F, Panteghini M. Laboratory medicine in the new healthcare environment. Clin Chem Lab Med. 2016; 54(4): 523-33. PubMed PMID: 26466169.

22. Singh H, Arora HS, Vij MS, Rao R, Khan MM, Petersen LA. Communication outcomes of critical imaging results in a computerized notification system. J Am Med Inform Assoc. 2007; 14: 459-66.

\section{CORRESPONDING AUTHOR}

Wilson Shcolnik ID 0000-0002-9154-9183

e-mail: wilson.shcolnik@grupofleury.com.br

\section{$(\mathrm{cc}))_{\mathrm{EY}}$}

This is an open-access article distributed under the terms of the Creative Commons Attribution License. 